\title{
Logística Reversa de Embalagens de Medicamentos Veterinários: Um Nicho Inexplorado pela Ecoinovação
}

\author{
$\underline{\text { Sebastião Sergio Prestes de Limal'; Juliane Sachser Angnes }}{ }^{d}$ \\ $\triangle \underline{\text { sbrayan2003@yahoo.com.br }}$
}

1. Universidade Estadual do Centro-Oeste (UNICENTRO).

\author{
Histórico do Artigo: \\ Recebido em: 11 de maio de 2020 \\ Aceito em: 20 de julho de 2020 \\ Publicado em: 31 de dezembro de 2020
}

Resumo: As políticas para uma sociedade baseada em produção sustentável estão em notória discussão. Especialmente, uma produção que se preocupe com inovações de bem estar social, econômico e ambiental, aqui representado pela ecoinovação, entretanto, alguns setores produtivos ainda se desenvolvem aquém dessa realidade. A indústria de produtos veterinários é uma delas, qual possui uma alta representatividade econômica no Brasil. 0s resíduos sólidos oriundos das vacinas, medicamentos, aditivos alimentares entre outros, não possuem normatização sobre descarte adequado. Assim, o objetivo da pesquisa é compreender a existência de condutores de ecoinovação que possam auxiliar na logística reversa de embalagens de produtos de uso veterinário, na cidade de Guarapuava no Estado do Paraná. Para consecução do estudo, uma abordagem qualitativa se fará presente. Um estudo de caso, no final da cadeia dos produtos veterinários, de maneira descritiva caracterizará a compreensão da logística reversa. Além do que, um gerente de uma revenda e três produtores rurais foram entrevistados, e posteriormente, realizada uma análise de conteúdo. As duas perspectivas do fenômeno contribuíram com a triangulação dos dados, junto a legislação vigente e literatura da ecoinovação. Portanto, conclui-se a existência de uma demanda por uma logística reversa regulamentada na indústria veterinária, norteada por determinantes de ecoinovação.

Palavras-chave: Ecoinovação, Logística Reversa, Medicamentos, Produtos Veterinários.

\section{Reverse Logistics of Veterinary Medicine Packaging: A Nich Unexplored by Ecoinnovation}

\begin{abstract}
Policies for a society based on sustainable production are in clear debate. Especially, a production that is concerned with innovations in social, economic and environmental well-being, represented here by eco-innovation, however, some productive sectors still develop below this reality. The veterinary products industry is one of them, which has a high economic representation in Brazil. Solid residues from vaccines, medications, food additives, among others, do not have standards for proper disposal. Thus, the objective of the research is to understand the existence of eco-innovation drivers that can assist in the reverse logistics of packaging for veterinary products, in the city of Guarapuava in the State of Paraná. To carry out the study, a qualitative approach will be present. A case study, at the end of the veterinary product chain, in a descriptive manner will characterize the understanding of reverse logistics. In addition, a resale manager and three rural producers were interviewed, and subsequently, a content analysis was carried out. The two perspectives of the phenomenon contributed to the triangulation of the data, along with the current legislation and the eco-innovation literature. Therefore, it is concluded that there is a demand for regulated reverse logistics in the veterinary industry, guided by eco-innovation determinants.
\end{abstract}

Keywords: Eco-innovation, Reverse logistic, Medicines, Veterinary products. 


\section{Logística Inversa del Embalaje de Medicamentos Veterinarios: Un Nicho No Explotado por la Ecoinnovación}

Resumen: Las políticas para una sociedad basada en la producción sostenible están en claro debate. Especialmente, una producción que se preocupa por las innovaciones en el bienestar social, económico y ambiental, representada aquí por la ecoinnovación, sin embargo, algunos sectores productivos aún se desarrollan por debajo de esta realidad. La industria de productos veterinarios es una de ellas, que tiene una alta representación económica en Brasil. Los residuos sólidos de las vacunas, medicamentos, aditivos alimentarios, entre otros, no tienen normas para su eliminación adecuada. Por lo tanto, el objetivo de la investigación es comprender la existencia de impulsores de ecoinnovación que pueden ayudar en la logística inversa de los envases para productos veterinarios, en la ciudad de Guarapuava en el Estado de Paraná. Para llevar a cabo el estudio, estará presente un enfoque cualitativo. Un estudio de caso, al final de la cadena de productos veterinarios, de manera descriptiva caracterizará la comprensión de la logística inversa. Además, se entrevistó a un gerente de reventa y tres productores rurales, y posteriormente se realizó un análisis de contenido. Las dos perspectivas del fenómeno contribuyeron con la triangulación de los datos, junto con la legislación vigente y la literatura sobre ecoinnovación. Por lo tanto, se concluye que existe una demanda de logística inversa regulada en la industria veterinaria, guiada por los determinantes de la ecoinnovación.

Palabras clave: Ecoinnovación, Logística inversa, Medicamentos, Productos veterinarios.

\section{INTRODUÇÃo}

0 desenvolvimento econômico oportuniza benefícios à sociedade, uma vez que gera empregos a população. Porém, quando este crescimento não considera o meio ambiente um recurso finito, consequências inconvenientes podem afetar a existência de sistemas naturais e seres vivos na terra. Jacomossi et al. 2016) identificaram diversos termos (inovação sustentável, inovação verde, inovação ecológica, ecoinovação, e inovação social) presentes na gestão organizacional de empresas preocupadas com a vigente temática. Entretanto, a expressão "ecoinovação" possui uma definição com maior proximidade a elaboração de produtos e processos inovadores. Para Rennings (2000) diversas coletividades podem exercer a ecoinovação tais como: empresas públicas, privadas, organizações não governamentais, além das próprias pessoas em suas residências. Sua definição se pauta em desenvolver novas ideias, comportamentos, produtos e processos, que aplicados ou introduzidos contribuem para redução de encargos ambientais ou para metas ecológicas específicas de sustentabilidade” (RENNINGS, 2000, p. 4). A ecoinovação deve ser instituída nos novos hábitos de uma sociedade preocupada com a preservação e recuperação de recursos já assolados.

Vinculado ao modelo da sociedade contemporânea, a ecoinovação deve estar presente em toda cadeia logística direta e reversa dos produtos. Os altos índices de produção e consumo acabam por gerar uma gama de resíduos sólidos, que nem sempre participam dos programas de 
reciclagem, potencializando ainda mais a poluição do planeta. A logística reversa dos resíduos é desempenhada de modo mais complexo, pois a medida que se distancia da organização que a produziu, minimizam-se as chances de que todos os envolvidos possuam as mesmas concepções de descarte consciente (BABIERI, 2012). A efetividade da logística reversa depende da atuação de toda uma sociedade.

Por esta razão, a pesquisa possui um objeto de estudo ainda imaturo frente a logística reversa. As embalagens de produtos veterinários será o locus especulativo deste movimento a jusante. Quando comparado o nível de perigo ao uso de produtos agrotóxicos, que possuem uma legislação vigente determinando uma logística reversa, se observa uma lacuna ainda a ser preenchida. A Lei 9.974, de 06 de junho de 2000, apresenta uma regulamentação frente a captação e destinação correta de embalagens de produtos agrotóxicos (BRASIL, 2000). Existe recolhimento em cerca de $94 \%$ dos de resíduos sólidos no Brasil da indústria agroquímica (INPEV, 2015). Entretanto, não há dados sobre o retorno de embalagens de medicamentos agropecuários. Tramitam no Congresso Projetos de Lei (PLs) números 134/2007 e 718/2007, que propõem a alteração do Decreto-Lei no 467/1969, para que haja responsabilidade sobre os acondicionamentos de produtos veterinários (ROSSET0, 2013). Identificou-se também, uma petição enviada ao Senado Federal no dia 7 de abril de 2011, que pede a alteração da vigente Lei 12.305 sobre Políticas de Resíduos Sólidos. A petição requer disciplina para o descarte de embalagens de medicamentos de uso humano quanto veterinário.

Maçaneiro et al (2015) compreenderam que esforços externos à organização devem ser essenciais para a promoção de ações ecoinovativas. Neste estudo, observaram-se as regulamentações ambientais como fator prepotente para a inserção de atividades de ecoinovação na gestão de uma empresa de papel e celulose. Logo, pode-se inferir que as normatizações são vistas como oportunidade de desenvolvimento e não com percepções que tendem a prejudicar as empresas. Neste sentido, a ausência de normas sob o contexto dos acondicionamentos de fármacos veterinários tende a minimizar as chances de se obter uma logística reversa instituída.

A pergunta problema se intitula: como determinantes de ecoinovação podem ser efetivados na logística reversa de produtos veterinários?

Assim, o objetivo desta pesquisa se concentra em compreender a existência de condutores de ecoinovação que possam auxiliar na logística reversa de embalagens de medicamentos de uso veterinário, no município de Guarapuava - PR. Para consecução deste objetivo, a pesquisa conta com uma abordagem qualitativa, que irá investigar a perspectiva de 
três pecuaristas e uma revendedora de produtos veterinários. A coleta de dados se dará por meio de entrevistas semiestruturadas.

A escolha do local se faz relevante, uma vez que há incidência da atividade agropecuária na região, sendo utilizados inúmeros tipos de vacinas e medicamentos veterinários. Quando descartados de maneira imprudente podem gerar uma grave ameaça à saúde pública. Não obstante, o problema não se justifica apenas em âmbito local, mas também nacional. Uma vez que o Brasil está entre os cinco maiores mercados da indústria veterinária, motivado pela exportação e exigência de padrões sanitários para produção (CAPANEMA, et al. 2007).

A instituição da logística reversa oportuniza ganhos de diversas naturezas. Para Leite (2009), a economia tende a crescer, visto que o transporte reverso se fará necessário, uma nova indústria precisa preparar o material para ser reciclado, além de todos os stakeholders envolvidos. Eminente são os aspectos positivos ao meio ambiente, que não sofrerá com 0 acúmulo de resíduos sólidos, mantendo a fauna e flora dos ambientes. Concomitantemente, a saúde humana se beneficiará, quanto a redução de poluentes nos diversos âmbitos com que se relacionam.

Como essa cadeia reversa não possui uma regulamentação, a pesquisa tende a estabelecer esse canal reverso se baseando nos princípios de ecoinovação.

\section{Logística Reversa}

Fazer com que o ciclo produtivo seja concluído com a reciclagem de seus resíduos sólidos é uma tarefa árdua, que exige compromisso de todos os envolvidos. Barbieri (2012, p. 240) destaca que "a gestão da cadeia de suprimento em geral não alcança a totalidade da cadeia, principalmente em cadeias longas ou com muitos fornecedores e pontos de vendas disseminados em muitos locais, regiões ou países [...]”. Assim, não há como responsabilizar apenas os fabricantes, pois à medida que são comercializados todos precisam tomar sua parcela de comprometimento, para que o ciclo produtivo não afete o desenvolvimento ambiental.

Notoriamente Guarnieri (2011) preconiza que a sustentabilidade efetivada nos negócios requer inovações indispensáveis na perspectiva do processo produtivo pleno. Uma delas é a logística reversa, mediante a qual, há que se repensar sobre o intercurso dos resíduos sólidos, mediante inovações e alterações que agregam melhor controle e finalidade aos resíduos, custos, cadeia de suprimentos e outros. Em contexto contemporâneo a logística reversa, segundo Leite (2009), conota o planejamento, as práticas e o controle do fluxo e das informações logísticas 
pertinentes aos bens de pós-venda e de pós-consumo no ciclo operacional do negócio. Os bens de pós-venda são produtos que chegam até os consumidores/usuários com determinado defeito e precisam voltar a linha de produção, para conserto ou desmanche. Os de pós-consumo são os que efetivamente concluíram sua função e, precisam ser descartados integralmente ou suas embalagens. Assim sendo, a logística reversa oportuniza, pelos meios formais, como normatizações dos setores, legislações e institucionalizações, ao surgimento de novos mercados.

Para Marchi (2011, p. 119) a logística reversa se representa "por ações destinadas a facilitar a coleta e a restituição dos resíduos sólidos aos seus geradores, para que sejam tratados ou reaproveitados em novos produtos, na forma de novos insumos, em seu ciclo ou em outros ciclos produtivos, visando a não geração de rejeitos”.

A inserção da logística reversa apenas oportuniza benefícios a sociedade, diminuir os acréscimos aos aterros sanitários é um dos desafios do século. Essas ações precisam estar inseridas em toda cadeia. pois a reciclagem ou reuso depende dos modelos de produção instituído A logística reversa foi considerada como uma das ferramentas que uma organização pode utilizar para tentar reduzir as intervenções ambientais predatórias e seus impactos, além de se mostrar capaz de propiciar retornos financeiros ou ainda redução de custos (CORREA; SILVA, 2013, p. 22). Assim, é possível diagnosticar uma gestão integrada com todos os envolvidos na cadeia.

Segundo Moraes (2013) é obrigação legal dos fabricantes, importadores, distribuidores e comerciantes as ações e investimentos para que os produtos após sua vida útil sejam reinseridos no fluxo direto ou reverso de suprimentos pela reutilização, remanufatura, reciclagem e/ou outas formas de destinação final correta perante as legislações ambientais.

No contexto brasileiro o mercado veterinário apresenta movimento adverso às práticas do setor produtivo rural. Visto que é considerado líder mundial na reciclagem de embalagens de defensivos agrícolas, atingindo a coleta de $96 \%$ do total de resíduos. Porém, não existindo evidências para o mesmo movimento em embalagens e demais resíduos de uso veterinário (MAPA, 2017). Exemplo não é apenas dos agrotóxicos, mas de produtos como pneus, pilhas, baterias e óleos lubrificantes, que possuem sólidos projetos de fluxo reverso (MARCHI, 2011). Inovações em toda a cadeia precisam ser instauradas, para que novos padrões de produtos, processo e comportamento auxiliem no fluxo reverso de resíduos sólidos. A instituição de inovações que beneficiam o meio ambiente é chamada de ecoinovações. Portanto, para que a ecoinovação seja compreendida neste processo de logística reversa, oportuno se faz identificar suas definições. 
Logística Reversa de Embalagens de Medicamentos Veterinários: Um Nicho Inexplorado pela Ecoinovação

\section{Fatores de Ecoinovação}

A ecoinovação possui discussões teóricas ainda em nível imaturo. Arundel e Kemp (2009) destaca a relevância de se estabelecer métricas que demonstrem a evolução dos benefícios, principalmente ambientais. Métricas que devem evidenciar a natureza da ecoinovação, condutores e barreiras, além de seus efeitos. Assim, quatro categorias são compreendidas nesta gestão; a) tecnologias ambientais: são todos os equipamentos tecnológicos que não agridem o ecossistema, e se utilizam de recursos naturais sem apresentar danos; b) inovações organizacionais: normas que podem ser utilizadas como condutores da gestão organizacional, como a ISO 14.001; c) inovações de produtos e serviços: possuem relação direta com os consumidores e usuários de serviços, tende a mudar hábitos e padrões já instituídos, com o uso de produtos que não agridam o ambiente; d) sistemas de inovação verde: são realmente novas maneiras de realizar uma atividade, como a agricultura orgânica. Estas categorias se entendem a todos os envolvidos em uma cadeia de suprimentos, fato que demanda estudos que possam minimizar a distância entre os envolvidos. A produção, consumo e descarte de resíduos precisam ser pensados de maneira mútua.

A sociedade atual possui fatores determinantes que impulsionam o aumento de práticas de inovação em cordialidade com o meio ambiente. Atualmente duas grandes vertentes são destaques, a economia ambiental e economia inovativa. "Enquanto a economia ambiental explica como acessar instrumentos de políticas ambientais, a economia inovativa tem proporcionado percepções sobre a complexidade de fatores que influenciam as decisões inovativas" (RENNINGS, 2000, p. 324). Assim, se observa a busca e as pressões que podem influenciar a mudança nas organizações e, consequentemente, na sociedade. Rennings (2000) evidencia que as regulamentações são boas condutoras de inovações, porém orientadas por padrões técnicos, que podem ser substituídos por acordos entre governo e empresas. Neste sentido, as empresas trabalham dentro de um processo de estímulo e resposta, ou seja, apresentam ações reativas aos problemas. Empresas que atuam com perspectiva em ecoinovação poderão ver isso como um custo e não como oportunidades que podem ser exploradas a favor do desenvolvimento organizacional. A Figura 1 demonstra fatores impulsionadores que podem efetivar ações de ecoinovações. 


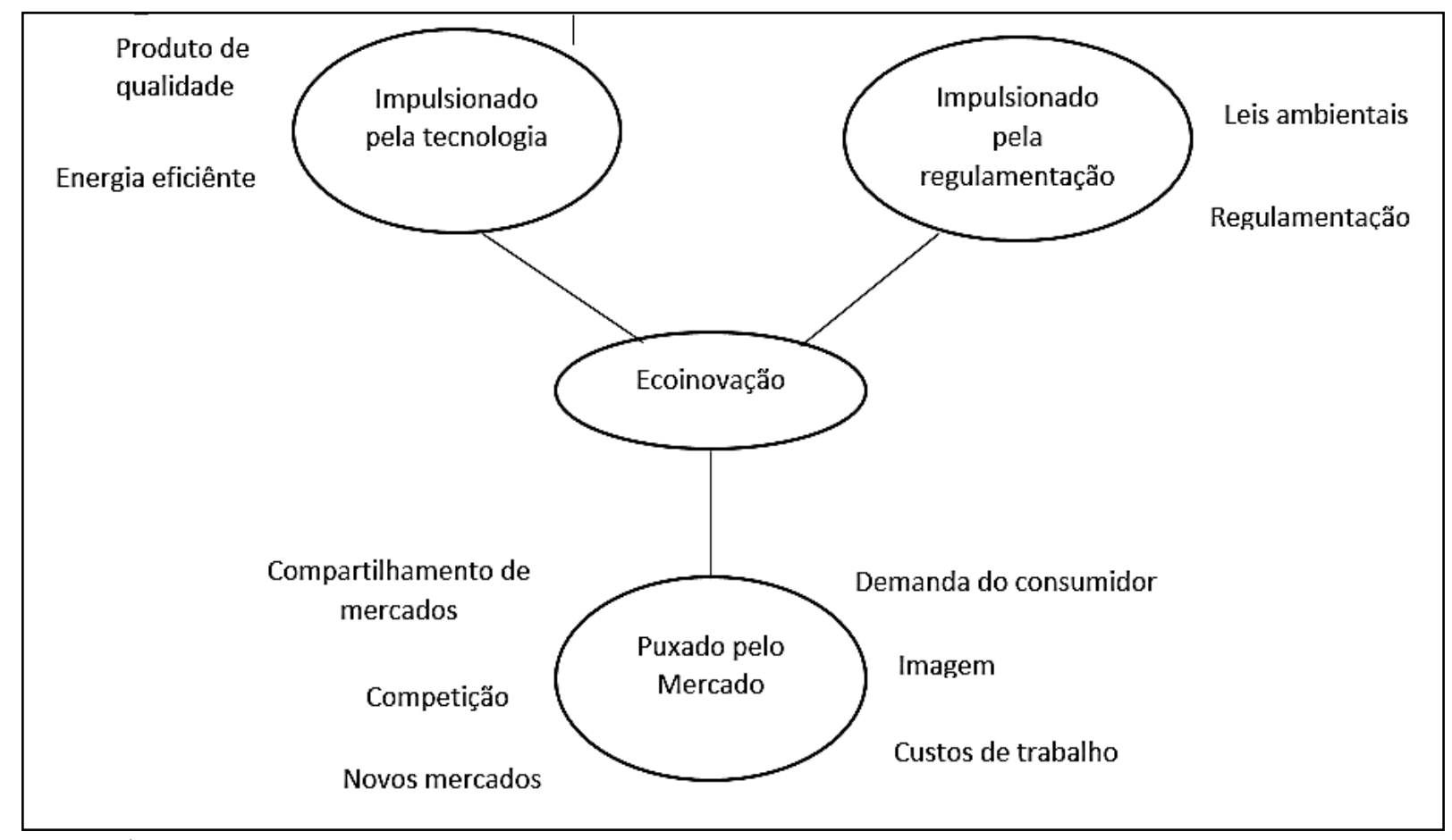

Figura 1. Determinantes de ecoinovação

Fonte: Adaptado de Rennings (2000, p 326).

A economia inovativa demonstra um panorama influenciador de ações benéficas ao meio ambiente. Estes determinantes de ecoinovação (Figura 1) são estímulos a soma da regulamentação, tecnologia e mercado se tornam indispensáveis a efetivação da ecoinovação. A regulamentação por si só não institui novos hábitos, assim o mercado consumidor/usuário possui grande responsabilidade, uma vez que suas escolhas tendem a pressionar uma produção mais limpa. Assim, a escolha por inovações tecnológicas se torna investimentos revertidos em vantagens para a organização, seja no aperfeiçoamento do produto, menor custo de produção, entre outros (RENNINGS, 2000). A ecoinovação pode oportunizar ganhos concretos à organização, tornando possível o desenvolvimento tecnológico associado ao bem estar do ecossistema.

Embora várias razões creditem resultados positivos à empresa, muitas ainda possuem resistência a inserção de novos métodos de produção. Carrillo-Hermosilla, Río e Könnölä, (2010) destacam algumas barreiras que minimizam as chances de organizações praticarem ecoinovações. A existência de barreiras econômicas, tecnológicas e institucionais instigam circunstâncias que ocorrem internamente e externamente à organização, além das características das ecoinovações. Sob fatos internos da organização, suas características precisam ser levadas em consideração como, situação financeira, tamanho, posição na cadeia de valor, idade, caráter nacional ou multinacional, produção voltada para exportação, 
Logística Reversa de Embalagens de Medicamentos Veterinários: Um Nicho Inexplorado pela Ecoinovação

características do setor, além da competência tecnológica disponível a implementação de mudanças. No que tange aos aspectos externos, políticas públicas, situação econômica, falta de informação, suprimentos, consumidores finais, competidores, associações industriais, sociedade civil, centros de pesquisas e instituições financeiras podem interferir na adoção de práticas ecoinovativas. Ademais, as particularidades das ecoinovações também precisam ser ponderadas, como os custos, benefícios potenciais, complexidade, compatibilidade com o sistema existente, inovações complementares, além dos critérios para acessar essas novas tecnologias. Todas essas barreiras são plausíveis de identificação em diferentes contextos, entretanto, os fatores benéficos precisam ser potencializados.

Além disso, a ecoinovação também ocorre nos processos fora das organizações, CarrilloHermosilla, Río e Könnölä, (2010) e Jacomossi et al. (2016) destacam as inovações sociais, quais se estendem ao comportamento dos indivíduos. Ao se referir a inovações que compreendem o fluxo reverso de resíduos, um esforço conjunto precisa ser realizado na mudança de hábitos. A pequena ação desempenhada por cada indivíduo fará a diferença na eficácia do projeto.

\section{Produtos Veterinários}

A inserção de ecoinovações precisam ser refletidas sob o conhecimento das características do setor, bem como a sua posição na cadeia de valor (CARRILLO-HERMOSILLA; RÍO; KÖNNÖLÄ, 2010). Portanto, essencial é compreender a indústria de medicamentos veterinários, para a identificação de possível práticas ecoinovativas na logística reversa de suas embalagens.

Impulsionado pela importação e exportação de matérias primas e produtos acabados, 0 setor agroquímico se consolida fortemente junto a indústria de agronegócio brasileira. Indispensável é a inserção de tecnologias e boas práticas de gestão para que se mantenham no mercado internacional (CARLARGE, STOLO, STOL0, 2007). Dada a dimensão do setor no país, se faz ainda mais necessário o controle de resíduos sólidos oriundos desta atividade.

0 Brasil se destaca por seu percentual de criação animal, bem como, os seus derivados. A alta representatividade oportuniza ganhos econômicos em várias áreas. A diversidade de produtos veterinários demonstra uma gama de químicos que podem degradar o ecossistema, além de afetar o desenvolvimento de outros organismos. Atualmente, o Brasil conta com certa de 7.222 produtos veterinários, autorizados no território brasileiro (ROSSET0, 2013). 
Essa gama de fármacos subsidiam a criação de rebanhos de diferentes espécies. "Os produtos veterinários, assim como os farmacêuticos dedicados à saúde humana, são subdivididos em classes terapêuticas: parasiticidas, biológicos (vacinas), tratamento de infecções, aditivos alimentares e outros farmacêuticos” (CAPANEMA, et al. 2007, p. 159). A comercialização destes produtos gera o descarte de acondicionamentos de vidro ou plástico. Além destes resíduos sólidos, há o uso de equipamentos perfurantes, como agulhas, para aplicação de vacinas.

A responsabilidade acerca dos medicamentos veterinários é do Ministério da Agricultura Pecuária e Abastecimento (MAPA).

\footnotetext{
E, "busca integrar sob sua gestão os aspectos mercadológico, tecnológico, científico, ambiental e organizacional do setor produtivo e também dos setores de abastecimento, armazenagem e transporte de safras, além da gestão da política econômica e financeira para o agronegócio" (MAPA, 2017, p.l).
}

Para tanto, o Mapa institui políticas públicas, regulamentações e normatizações para 0 setor. Embora haja menção sob a gestão ambiental, as legislações existentes, específicas para os medicamentos veterinários, (Decretos-Lei números 467/1969, 1.662/1995 e 5.053/2004) não compreendem a logística reversa dos resíduos sólidos oriundos desta indústria.

Visto que estes medicamentos possuem níveis de toxidade Rosseto (2013, p.18) assevera, "importante ressaltar que praguicidas de uso veterinário e de uso agrícola têm semelhanças químicas e/ou estruturais e oferecem risco à saúde do trabalhador e ao meio ambiente”. 0s prejuízos se assemelham ao descarte indevido das embalagens de agrotóxicos. Assim, uma forte legislação e controle é realizada na logística reversa dos acondicionamentos de defensivos agrícolas. 0 que comprova a necessidade de uma legislação incidente também sobre esses resíduos sólidos de produtos veterinários.

Silva, Moreira e Peres (2012) realizaram um estudo, especificamente, com carrapaticidas, que releva o perigo destes medicamentos veterinários a saúde dos profissionais que os manipulam e, consequentemente, ao meio ambiente. Na análise das entrevistas, foi possível identificar uma ausência de conhecimento atrelado a toxidade dos medicamentos veterinários tanto a saúde humana quanto ao ecossistema. Percebe-se que os usuários não possuem instrução sobre os riscos à própria saúde, menos ainda, em relação aos prejuízos ambientais. Embora, o MAPA (2017) disponha de uma Coordenação de Fiscalização de Produtos Veterinários (PCV) presente em toda a cadeia de suprimentos dos produtos veterinários, há uma vulnerabilidade quanto a má utilização e descarte dos resíduos. 
Logística Reversa de Embalagens de Medicamentos Veterinários: Um Nicho Inexplorado pela Ecoinovação

\section{MATERIAL E MÉTODOS}

Os procedimentos metodológicos se inserem na conjuntura qualitativa. Esta abordagem se preocupa em diagnosticar especificidades de um fenômeno. A coleta de dados é realizada de modo a ouvir os sujeitos pesquisados, podendo emergir questões ainda não estabelecida pelo pesquisador (GODOI; MELO, SILVA, 2010). Assim, o corpus de pesquisa se incide no final da cadeia dos produtos veterinários, a fim de identificar condutores de ecoinovações na instituição de uma logística reversa.

Assim, a estratégia de pesquisa abrange um estudo de caso descritivo. Yin (2005) afirma que estudos de caso tendem a destacar seus limites dentro de um fenômeno, para compreendêlo de modo profundo. 0 fenômeno será descrito nos limites da conjuntura atual, o que também 0 caracteriza sob a ótica de uma análise transversal. Valendo-se de duas etapas fundamentais de pesquisa, realizou-se: a) pesquisa bibliográfica pertinente, empregando consulta em resoluções, normas, legislações, artigos, livros e sites governamentais; b) pesquisa empírica, sob duas visões divergentes do fenômeno estudado.

Como instrumento de coleta de dados, optou-se por entrevistas semiestruturadas. A qual se realizou junto a dois roteiros de entrevista, preocupados em identificar a rotina dos processos de utilização de medicamentos veterinários. 0 roteiro utilizado com 0 gerente da revenda, considerou compreender os produtos comercializados, se prestavam informações quanto a utilização e descarte dos resíduos sólidos. Analogamente, o roteiro dos produtores rurais ponderou o uso e descarte dos mesmos. Godoi, Melo e Silva (2010) asseveram que o uso de roteiros em entrevistas semiestruturadas auxilia na estruturação do conteúdo. As entrevistas foram realizadas no mês de julho de 2018, com duração média de 30 minutos cada, sendo realizada sua transcrição para a interpretação perante o escopo da pesquisa.

Posteriormente à coleta de dados, os mesmos foram investigados perante análise de conteúdo. A análise por categoria foi escolhida a fim de identificar semelhanças e divergências nos discursos dos entrevistados, e, consequentemente, estabelecer uma categorização dos assuntos abordados (BARDIN, 2016). Ademais, a triangulação dos dados se apresenta na análise final. Os dois tipos de entrevistas (gerente e produtores de rebanho bovino) contribuíram a triangulação dos dados, junto à legislação vigente e literatura da ecoinovação.

\section{RESULTADOS E DISCUSSÃ0}


Para consecução da análise, qual engloba a problemática: como determinantes de ecoinovação podem ser efetivados na logística reversa de produtos veterinários? E, possui objetivo de compreender a existência de condutores de ecoinovação que possam auxiliar na logística reversa de embalagens de medicamentos de uso veterinário, em um município do Estado do Paraná. Se realizará uma triangulação de dados, sob a ótica da literatura da ecoinovação, campo de estudo (orientado pela legislação vigente), sujeitos inseridos no processo (entrevistas semiestruturadas com uma revenda e três pecuaristas) com análise de conteúdo. Os pecuaristas entrevistados serão denominados A, B e C, o primeiro possui ensino superior, o segundo ensino médio incompleto e o terceiro dispõe de Pós graduação. Visto que o campo de estudo se estabelece dentro de um recorte da cadeia de suprimento da indústria de produtos veterinários (logística reversa dos resíduos sólidos) ainda não instituído legalmente. Destaca-se que este estudo pretende fomentar práticas baseadas na ecoinovação, que possam ser utilizadas na inserção de políticas públicas e normatização para o setor. Embora a pesquisa, de cunho qualitativo, esteja inserida em um contexto específico de uma cidade do interior do Paraná, a falta de legislação nacional nos faz inferir a gravidade do problema em outras realidades.

A dimensão da cadeia produtiva ultrapassa limites geográficos e é compartilhada por diferentes sujeitos, com interesses divergentes. 0 que dificulta o fechamento do ciclo de vida de produtos e resíduos sólidos, com descarte consciente (BARBIERI, 2012). Neste sentido, a pesquisa se preocupou em pesquisar dois tipos de participantes da cadeia dos medicamentos veterinários, o que oportuniza percepções divergentes de um mesmo fenômeno. Visto que a ecoinovação se baseia também em inovações sociais (JACOMOSSI et al, 2016), um trabalho de conscientização sobre os cuidados de uso dos medicamentos veterinários precisa ser propagado. Especialmente ao público que possui menor nível de instrução sob os riscos que podem ocasionar a saúde humana e ambiental. Portanto, o vínculo do consumidor final se associa as revendas destes medicamentos. Quando indagado se existia algum projeto para o recolhimento dos resíduos de uso veterinário, o gerente da revenda, não houve surpresa sobre o assunto.

"Já está em processo uma parceria com uma empresa que trabalha com esse processo
de fazer a captaça dos resíduos. A partir do momento que esse processo estiver
pronto, vamos conversar e orientar os nossos produtores de que forma separar esses
resíduos, por exemplo, perfurocortantes, agulhas, bisturis, embalagens vazias e
embalagens com restos de medicamentos vencidos. [...]a demanda surgiu através da
BPF (boas práticas na fazenda)"

Isso demonstra ecoinovações impulsionadas por aspectos econômicos, uma vez que, há busca por novos mercados (RENNINGS, 2000). 0 trabalho de uma empresa privada para a 
capitação destes resíduos sólidos, movimenta a inserção de novos postos de trabalho no transporte, triagem dos resíduos, empresas recicladoras, além do estímulo a pesquisas para 0 melhor aproveitamentos destes materiais. 0s materiais mencionados pelo gerente exigem atenção, visto que, se equiparam aos resíduos sólidos hospitalares. Objetos perfurocortantes com resíduos de medicamentos podem ocasionar danos a quaisquer seres vivos.

0 programa de gestão citado pelo gerente (BPF) é específico da indústria leiteira, os produtores podem aderir ao programa para se tornarem fornecedores à laticínios maiores, com maior representatividade. E dentre as várias práticas que oportuniza uma gestão de qualidade, a diminuição do impacto ambiental exige a logística reversa de resíduos sólidos. Barbieri (2012) assevera que Sistemas de Gestão Ambiental (SGA) são ótimos condutores de práticas sustentáveis. Assim, a competição do mercado (RENNINGS, 2000) oportuniza a qualificação dos processos produtivos. Neste sentido, programas como estes podem se tornar impulsionadores de ecoinovações.

Em relação a alguma orientação dada aos produtores rurais, o gerente da revenda afirma:

"Não existe nenhum tipo de orientação os vendedores, orientam no balcão de modo
geral quanto ao uso do medicamento, mas em relação à logística reversa, ainda não. A
gente quer começar assim que fechar o contrato com essa empresa, não sei se na nota
ou orientação a campo e orientação aqui na loja também. Nós como cooperativa temos
que acelerar o processo para que as empresas fabricantes de produtos veterinários
entrem nessa, como os defensivos agrícolas. Nos resíduos de embalagens veterinários
também tem algumas que podem ser recicladas e voltar ao ciclo de vida em outros
produtos".

Percebe-se a reafirmação do gerente quanto a contratação de uma empresa, para que possa realizar o trabalho de coleta reversa dos resíduos. Visto que os resíduos possuem uma semelhança aos defensivos agrícolas, os quais dispõem de uma legislação para o fluxo reverso, o gerente compreende essa necessidade legal. Uma vez que a revenda realiza o trabalho de informante do projeto de logística reversa dos defensivos agrícolas e não com produtos veterinários, isso se demonstra incoerente com a imagem da empresa. Pois ambos os produtos são comercializados nesta e em outras revendas. Assim, Rennings (2000) também destaca a imagem da organização como determinante a instituição de ecoinovações. Ainda, ao que se refere a barreiras de implementação de ecoinovações apresentadas por Carrillo-Hermosilla, Río e Könnölä (2010), a ausência de políticas públicas e legislações são determinantes para a inexistência de uma logística reversa de produtos veterinários. Fato que posiciona o Brasil em destaque quanto o recolhimento de embalagens de produtos agrotóxicos, mas se destitui quando os resíduos são da indústria veterinária. Neste sentido, até o momento os usuários de 
produtos veterinário destinam os produtos da maneira que determinam. 0 discurso dos produtores atesta essa situação que necessita de urgência mudança. Segundo a fala do produtor

A.

\begin{abstract}
"Após o uso nos fazemos à separação em sacos de raçoes ou de plásticos, onde eu faço o depósito das diferentes embalagens como: papel, plástico, vidros e outros separadamente, com a finalidade desse material separado, mandar para o lixão do município. A partir de certa época o lixão não recebe mais vidro, então eu estou com esse problema aqui, pois o vidro eu não consigo entregar em lugar nenhum, mas os plásticos até hoje o município está recebendo e, as embalagens de papel ou papelão certo ou errado eu estou queimando. Quanto aos perfurocortantes a partir de agora vou acondicionar em galões plásticos, pois hoje ainda deixo solto, por não ter onde entregar. Com o rebanho perto de 500 cabeças cada vez mais eu tenho mais resíduos que não tem onde descartar. Inclusive sobras de medicamentos como vacinas que tem que ser acondicionada em local refrigerado, quando há essas sobras é descartado juntamente com as embalagens no lixão, que por enquanto temos onde entregar”.
\end{abstract}

\title{
0 próximo parágrafo discorre sobre a fala do produtor B.
}

\begin{abstract}
"Deixamos separados tudo arrumadinho em caixas que nós ganhamos, aquelas caixas amarelas que são bem reforçadas e, após o uso era jogado no buraco da fossa. Até a própria veterinária, quando fazia a vacina da brucelose, ela descartava até a luva dentro da fossa, inclusive sobras de vacinas da aftosa que depois de sair do refrigeramento não pode ser utilizada também ia pra fossa, quanto aos perfurocortantes no caso das agulhas nós não utilizamos agulhas descartáveis, pois após o uso elas são esterilizadas podendo ser reutilizadas novamente. Os vidros tem muito pouco hoje, o mais é embalagens de plástico como os desverminantes, vidros somente os de ampolas que também são jogados no buraco, acho que seria muito importante que as empresas começassem a olhar para esses resíduos como já existe nos agrotóxicos, pois o veneno da lavoura você tem onde entregar, porque o veterinário não é da mesma forma, pois os dois são considerados inseticidas”.
\end{abstract}

E finalizando com a fala do produtor $\mathrm{C}$.

\begin{abstract}
"Quando sobra eu faço a destruição imediatamente queimando as embalagens, com essas sobras. Até porque, não tenho nenhum recipiente para armazenar. Essa inclusive são orientações de médico veterinário que diz que se usou, sobrou, não vai mais utilizar, deve queimar imediatamente. Sobre os perfurocortantes como agulhas, algumas eu reutilizo e as que não são reutilizadas eu tenho armazenadas em uma caixa de isopor. Por não ter nenhuma orientação de destinação final, mesmo na hora da compra, independentemente de onde eu compro, esses produtos eu costumo comprar sempre em duas casas comerciais e, não tenho orientação das embalagens e possíveis sobras e medicamentos para destinação final”.
\end{abstract}

Analogamente, os três produtores rurais destinam os resíduos da maneira que acham conveniente. Seja enviando para o lixão da cidade, queimando ou descartando em fossas, na propriedade. Todas as maneiras são incoerentes a uma produção sustentável, ao enviar os resíduos para aterros sanitários ou em fossas domésticas, contaminações no solo ou em seres 
vivos podem ocorrer. Marchi (2011) destaca que os aterros sanitários brasileiros misturam resíduos sólidos e orgânicos o que dificulta ainda mais reutilização de alguns materiais. No caso de resíduos veterinários não poderiam ser destinados aos aterros, devido ao grau tóxico que apresentam.

Divergente do estudo de Silva, Moreira e Peres (2012) sobre os entrevistados, no interior de São Paulo, que não reconheciam perigo em relação aos produtos e resíduos dos produtos veterinários. 0s produtores deste estudo, oriundos do interior do Paraná, conseguem identificar que esses produtos possuem riscos e prejuízos à saúde humana, meio ambiente e demais seres vivos. 0s discursos dos entrevistados são semelhantes, embora sejam produtores de rebanhos bovinos de grande porte (produtor A, com 500 unidades), médio porte (produtor B, com 120 unidades) e pequeno porte (produtor C, com 12 unidades). Segundo o produtor A

\footnotetext{
“A vacina da brucelose é muito perigosa, por se tratar de um agente atenuado, que com o contato no ser humano pode vir a contaminá-lo e, essa vacina só pode ser manipulada por especialista. Então isso deveria ser tratado como lixo hospitalar, pois traz grandes riscos a vida humana”
}

Na sequência o produtor B também refere-se a vacina da brucelose.

\begin{abstract}
“A vacina da brucelose ela não pode ser feita por nós, mas sim por veterinários que estão habilitados, pois essa vacina é muito perigosa. Se entrar em contato com a pele vai transmitir a doença causada por esse vírus. E posso dizer que esses profissionais estão menos preparados do que nós, pois só utilizam uma luva simples para fazer a vacina no rebanho e também jogam tudo na fossa. Acho que eles deveriam ser os responsáveis e recolher esses resíduos por se tratar de algo perigoso. Tem produtos que é até mais perigoso quando em contato com a pele dentro dos produtos veterinários e, mesmo assim não são recolhidos. Não existe por parte da revenda nenhuma orientação nem de como guardar e, nem como fazer o descarte destas embalagens, cada produtor descarta da sua maneira, portanto nunca foi criado nada para melhorar o processo de descarte destes resíduos, pois alguns queimam, outros enterram”.
\end{abstract}

0 fenômeno precisa de atenção especial, posto que, os próprios especialistas não estão se preocupando com os resíduos produzidos. 0 caso da vacina da brucelose demonstra que atenuantes graves podem afetar a saúde humana. Essa temática precisa ser polemizada amplamente, para que impulsionadores legais possam mudar o sentido negativo desta atividade. 0 discurso do produtor A apresenta uma analogia ao lixo hospitalar, qual possui um cuidado especial. Portanto, consumidores/usuários possuem conhecimento sobre os prejuízos ocasionados pelas ações equivocadas do pós-consumo dos produtos veterinários. CarrilloHermosilla, Río e Könnölä, (2010) destacam que o comportamento dos usuários é de suma 
relevância a efetivação de ecoinovações sociais. Porém, a mudança de hábitos pode levar algum tempo, neste sentido outros impulsionadores precisam estar presentes, como legislações acompanhadas de inspeções e políticas públicas. Assim, o processo de transformação comportamental será acelerado. E para que haja a instituição legal dessas normas, o tema necessita ser discutido em diversos meios, com o objetivo de obter atenção dos governantes. Essa afirmação vai de encontro a fala do gerente da revenda: "quero dizer que é muito importante 0 interesse por esta pesquisa e, incentivo você a continuar disseminando a importância da logística reversa, porque a gente vem a tempos pensando como nós vamos resolver essa questão" (GERENTE, 2018). A preocupação dos envolvidos é nítida, não há como ignorar este assunto.

\section{CONCLUSÃO}

0 fenômeno estudado oportunizou reflexões mais profundas, acerca dos riscos proporcionados por resíduos sólidos da indústria de produtos veterinários. A situação é preocupante, uma vez que, a produção agrícola brasileira se faz presente em grande parte do território nacional, de maneira excessiva. Embora o estudo tenha priorizado a compreensão de produtores de bovinos, tantas outras criações dependem de produtos veterinários e, não possuem uma destinação de resíduos regulamentada. Os três discursos analisados obtiveram semelhanças na retórica. 0s produtores de rebanhos bovinos percebem a necessidade de uma logística reversa de todos os resíduos produzidos pela atividade agropecuária.

Sob a ótica da ecoinovação, caracterizada por inovações de referência sustentável, que considera não só a mudança de novos produtos e/ou processos, mas também a alteração de comportamento sociais. Identificou-se a existência de reais condutores à inserção de um programa de logística reversa dos resíduos sólidos veterinários. Condutores estes que podem gerar mudanças na própria produção das embalagens dos produtos. Pois, ao passo que, a produção é pensada junto a reciclagem, as chances de manter ciclos econômicos sustentáveis se faz legítimo.

A inserção de projetos de ecoinovação oportuniza benefícios concretos ao bem estar da sociedade, meio ambiente, além da movimentação econômica. Ao destacar os condutores de ecoinovação da indústria veterinária, foi possível também identificar ganhos. 0 mercado, sendo um determinante de ecoinovação, é formado por diversos stakeholders. Os consumidores reivindicam a logística reversa, pois, suas propriedades, demais criações e pessoas envolvidas, 
podem ser contaminadas pelos resíduos. As revendas necessitam obter uma imagem confiável no mercado competitivo, pautando-se na sustentabilidade, suportam sua parcela de responsabilidade no processo de fluxo reverso. Novos mercados serão instituídos, o transporte, triagem, indústrias de reciclagem, entre outros de modo indireto, participarão do programa de logística reversa, movimentando a economia de modo positivo.

Outro determinante de ecoinovação é a inserção de legislação. Entretanto, não pode ser considerado um condutor, nesta pesquisa, e sim como uma barreira, pois a ausência de normatizações posiciona a atividade de modo vulnerável. Os produtores não possuem amparo, mesmo os veterinários, profissionais da área, culminam com atitudes que negligenciam 0 descarte consciente. Os governantes precisam se posicionar frente a este problema, para que leis e políticas públicas sejam instituídas de maneira urgente.

Embora a pesquisa tenha se fixado apenas no final da cadeia produtiva dos produtos veterinários, e mais especificamente com produtores de rebanho bovino, a falta de legislação em âmbito nacional tende a replicar ocorrências semelhantes no setor agrícola, nos mais diversos locais do país. Mas, para que o assunto obtenha uma repercussão ainda maior, oportuno se faz a realização de pesquisas com abordagens quantitativas. A comunidade acadêmica precisa externalizar os problemas da nossa sociedade, que podem ser solucionadas com a inserção de políticas públicas e legislações. 0 fato de os defensivos agrícolas possuírem uma logística reversa de seus resíduos sólidos, não nos deixa dúvidas sobre a instituição de um programa similar.

\section{REFERÊNCIAS BIBLIOGRÁFICAS}

ARUNDEL, A.; KEMP, R. Measuring eco-innovation. 2009.

BARBIERI, J. C. Gestão ambiental empresarial: conceitos, modelos einstrumentos.3. ed. São Paulo: Saraiva, 2012. BARDIN, L. Análise de conteúdo. São Paulo: Edições 70, 2016.

BRASIL. Lei 9.974, de 06 de junho de 2000. Institui a Política Nacional de embalagens de agrotóxicos e dá outras providências.

Decreto $\mathrm{n}^{0}$ 5053, de 22 de abril de 2004. Aprova o regulamento de fiscalização de produtos de uso veterinário e dos estabelecimentos que os fabriquem ou comerciem, e dá outras providências. Diário Oficial da União, Brasília, 23 abr. 2004a. 2010.

Lei 12.305, de 02 de agosto de 2010. Institui a Política Nacional de Resíduos Sólidos e dá outras providências.

CARRILLO-HERMOSILLA, J.; DEL RÍO, P.; KÖNNÖLÄ, T. Diversity of eco-innovations: Reflections from selected case studies. Journal of Cleaner Production, v. 18, p. 1078-1083, 2010. 
CAPANEMA, L. X. de L. et al. Panorama da indústria farmacêutica veterinária. BNDES Setorial, n. 25, p. 157-173, mar. 2007.

CALARGE, F. A.; SATOLO, E. G.; SATOLO, L. F. Aplicação do sistema de gestão da qualidade BPF (boas práticas de fabricação) na indústria de produtos farmacêuticos veterinários. Gest. Prod., São Carlos, v. 14, n. 2, p. 379-392, 2007.

CORREA, A. P. M.; SILVA, M. E. da. A logística reversa sob a perspectiva produção-mercado-consumo: o caso Boticário. GeAS - Revista de Gestão Ambiental e Sustentabilidade, v. 2, n.1, p. 97-122, 2013.

G0DOI, C. K.; MELO, R. B. de.; SILVA, A. B. (org.). Pesquisa qualitativa em estudos organizacionais: paradigmas, estratégias e métodos. 2. Ed. São Paulo: Saraiva, 2010.

GUARNIERI, P. Logística Reversa: em busca do equilíbrio econômico e ambiental. Recife: Editora Clube de Autores, 2011.

INPEV, Instituto Nacional de Processamento De Embalagens Vazias. Relatório anual de 2015. Disponível em: < http://www.inpev.org.br/educacao/publicacoes >. Acesso em: 10 jan. 2017.

JACOMOSSI, R.; DEMAJOROVIC, J.; BERNARDES, R.; SANTIAG0, A. L. Fatores determinantes da ecoinovação: um estudo de caso de fatores a partir de uma indústria gráfica brasileira. Gestão \& Regionalidade, v. 32, n. 94, p.101-117, jan/abr. 2016.

LEITE, P. R. Logística reversa: meio ambiente e competitividade. 2. Ed. São Paulo, Pearson Prentice Hall, 2009.

MAÇANEIR0, Marlete Beatriz et al. A regulamentação ambiental conduzindo estratégias ecoinovativas na indústria de papel e celulose. RAC-Revista de Administração Contemporânea, v. 19, n. 1, 2015.

MAPA - Ministério da Agricultura, Pecuária e Abastecimento. Estatística: Pecuária. 2017 Disponível em: < http://www.agricultura.gov.br > acesso: 26 de set. 2018.

MARCHI, Cristina Maria Dacach Fernandez. Cenário mundial dos resíduos sólidos e o comportamento corporativo brasileiro frente à logística reversa. Perspectivas em Gestão \& Conhecimento, v. 1, n. 2, p. 118-135, 2011.

MORAES, P. V. D. P. Macrorrelação ambiental de consumo: responsabilidade pós-consumo ou relação coletiva de consumo? Porto Alegre: Livraria do advogado, 2013.

RENNINGS, Klaus. Redefining innovation eco-innovation research and the contribution from ecological economics. Ecological economics, v. 32, n. 2, p. 319-332, 2000.

ROSSET0, R.. Diagnóstico dos resíduos sólidos do setor agrossilvopastoril: resíduos sólidos inorgânicos. Brasília: IPEA, 2013.

SILVA, T. P. P. da; MOREIRA, J. C.; PERES, F. Serão os carrapaticidas agrotóxicos? Implicações na saúde e na percepção de riscos de trabalhadores da pecuária leiteira. Ciência \& Saúde Coletiva, v. 17, p. 311-325, 2012.

YIN, R. K. Estudos de caso: planejamento e métodos. Porto Alegre: Bookman, 2005. 